\title{
REVISÃO SISTEMÁTICA SOBRE AVALIAÇÕES REPRODUTIVAS EM OVINOS
}

\author{
Michele da Rosa Scholant Simões ${ }^{1}$
}

RESUMO: O presente trabalho teve como objetivo uma revisão sistemática das metodologias de avaliação reprodutiva dos ovinos. Tendo como objetivo a análise de sêmen ovino, para observação da motilidade e vigor nas amostras coletadas. Revisando as metodologias do uso do eletro ejaculador na coleta de sêmen ovino, visto que quando a prática está inserida e associada com a teoria tem-se um aprendizado mais eficiente, ressaltando a importância da literatura aderida ao material prático e a adaptabilidade com a realidade.

Palavras-chave: Manejo. Reprodução. Ovinocultura.

ABSTRACT: The present work had as objective a systematic revision of the methodologies of reproductive evaluation of the sheep. Having as objective the analysis of sheep semen, to observe the motility and vigor in the collected samples. Reviewing the methodologies of the use of the electro ejaculator in the collection of ovine semen, since when the practice is inserted and associated with the theory there is a more efficient learning, emphasizing the importance of the literature adhered to the practical material and the adaptability to reality.

Keywords: Management. Reproduction. Sheep farming.

\section{INTRODUÇÃO}

O ovinos domésticos (Ovis aries), uma das primeiras explorações animais feitas pelo homem, há mais de 4.000 anos a.C., na Ásia Central; e sua exploração é destinada à produção de alimento, na forma de carne e leite, e de outros produtos, tais como lã e pele.

Sabendo-se que a ovinocultura está diminuindo consideravelmente no estado do Rio Grande do Sul, com os dados obtidos pelo IBGE (Instituto Brasileiro de Geografia e Estatística), em 2006 havia um pouco menos de quatro milhões de cabeças no estado, enquanto que na década de setenta era uma pouco mais que 12 milhões, enquanto as lavouras, produção de bovinos, caprinos, aves e suínos vem aumentando. Porém está ressurgindo aos poucos o interesse do consumo da carne ovina de qualidade, sendo uma alternativa bastante importante para a atividade pecuária.

As biotecnologias são necessárias para organizar este mercado permitindo a

\footnotetext{
${ }^{\text {I }}$ Médica veterinária. Doutora em melhoramento genético pela UFPEL.
} 
utilização racional do rebanho, orientando o produtor no manejo das matrizes na sua propriedade até a aquisição do reprodutor. Este trabalho visa descrever o aprendizado destas tecnologias na área de reprodução ovina.

\section{REVISÃO DE LITERATURA}

\section{FISIOLOGIA REPRODUTIVA DO MACHO}

Segundo Mies Filho (1987), o aparelho genital do macho é composto por um parde gônadas masculinas (testículos), vias espermáticas (tubos retos, rete testis, canais eferentes, epidídimo e canal deferente), glândulas anexas (vesículas seminais, próstata, glândulas de Cowper ou Bulbos-uretrais e glândulas de Littre ou glândulas uretrais), órgão copulador (pênis ou verga), bolsa escrotal (pele ou escroto) e prepúcio (camada de pele que protege o pênis), conforme visualizado na figura um.

Aisen (2008) cita que cada ducto ou canal deferente, ao final de sua trajetória possui uma dilatação, denominado ampola, tendo como função reservatório espermático.

De acordo com Aisen (2008), os testículos têm dupla função que é espermatogênese e esteroidogênese, onde as células responsáveis são as chamadas células de Sertoli e Leydig respectivamente.

Conforme Hafez (2004), os testículos são compostos por células que secretam hormônios masculinos chamada de células de Leydig, que se situam entre os túbulos seminíferos e ainda possuem as células de Sertoli (células de sustentação).

Para Aisen (2008), estas células de Sertoli encontram-se dentro dos túbulos seminíferos, possuem a função de sustentar as espermatogônias e produção de fluídos para o transporte dos espermatozóides até a rete testis. Del Campo (1980) cita que as células de Leydig produzem o hormônio masculino chamado testosterona.

Aisen (2008), relata que o epidídimo divide-se em cabeça, corpo e cauda, onde nesta é feito o armazenamento das células maduras e naquelas é realizada a maturação dos espermatozóides. Os ductos deferentes transportam as células desde a cauda do epidídimo até a porção pélvica da uretra. Em conjunto, as glândulas anexas produzem secreções que contribuem para formação do plasma seminal.

Ainda o autor enfatiza que as vesículas seminais secretam a maior parte do líquido seminal. As glândulas bulbos-uretrais produzem um plasma rico em substâncias que 
nutre o espermatozóide, mantém seu metabolismo, limpa a uretra e antes da ejaculação, lubrifica o pênis, sendo este o órgão copulatório.

Figura I - Desenho esquemático do aparelho genital do macho

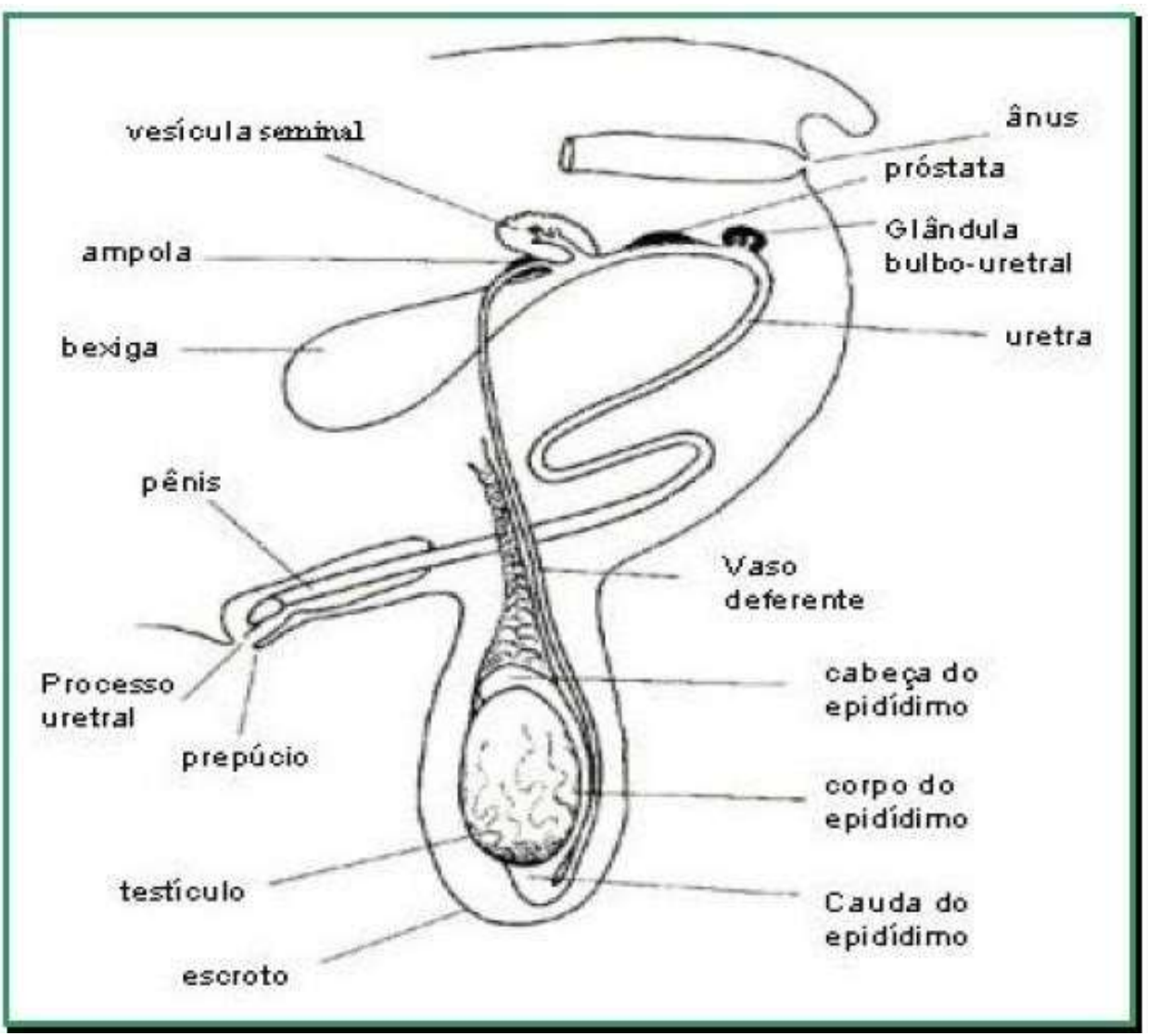

Fonte: Granados, Luis Bernabe Castillo, 2006

\section{ESPERMATOGÊNESE}

González (2006) cita que este fenômeno é um conjunto de transformações e divisões citológicas que resulta na formação do espermatozóide. Afirmando também que esta é interrompida durante o período de inatividade sexual, ou seja, fora da estação reprodutiva.

Os mais importantes eventos na espermatogênese são as renovações de células germinativas por mitose, redução do número de cromossomos por meiose e a transformação de uma célula convencional em uma complexa estrutura móvel (espermatozóide), conforme González (2006).

Para Mies Filho (1987) o processo de espermatogênese é constituído por um 
conjunto de transformações onde as células iniciais são espermatogônias seguidas de espermatócitos primários e secundários, espermátida e espermatozóide. Ainda este autor cita que entre a fase de transformação de espermatogônias a espermátidas denomina-se espermatocitogênese e entre as transformações de espermátidas até espermatozóides é denominada espermiogênese.

O processo de espermatogênese se estabelece após quatro etapas: fase de multiplicação, crescimento, maturação e diferenciação (MIES FILHO, 1987).

Para Hafez (2004) o processo de espermiogênese é dividido em quatro fases: fase de Golgi, fase de Capuchão, fase de Acrossomo e fase de Maturação.

Morfologia do Espermatozóide.

Mies Filho (1987) cita que as dimensões do espermatozóide varia conforme espécie, nos carneiros os valores aproximados em mícrons $(\mu)$ é para cabeça 8,2 $\mu$; peça intermediária é $14 \mu$, cauda é 40 a $45 \mu$, totalizando 62 a $67 \mu$ de comprimento.

De acordo com Hancock (1959) citado por Medeiros (2004) o espermatozóide é uma célula haplóide dotada de movimento, responsável por transportar o material genético do macho e determinação sexual.

É na cabeça do espermatozóide onde se encontra todo material genético do indivíduo, cromossomos que são constituídos por ácido desoxirribonucléico (DNA)(DEL CAMPO, 1980).

Segundo Derivaux (1980) citado por Medeiros (2004) o espermatozóide é dividido em cabeça, acrossomo e cauda, possíveis de serem visualizadas utilizando técnicas de colorações.

Hafez (2004) cita que a cabeça do espermatozóide é achatada de forma oval, contendo no seu interior cromatina altamente condensada. O acrossomo é uma estrutura que recobre a extremidade anterior do núcleo espermático apresenta-se em forma de dupla camada de membranas contendo enzimas hidrolíticas envolvidas no processo de fertilização.

Ainda o autor cita que a cauda está dividida em colo, peça intermediária, principal e terminal. Está assim dividido conforme estruturas que cada peça apresenta distintamente, o colo que constitui o ponto de união da cabeça com a cauda propriamente dita do espermatozóide, formando uma depressão no citoplasma; a parte central da peça intermediária junto com o comprimento total da cauda forma o axonema. 
O axonema é formado de nove pares de microtúbulos situados ao redor de dois filamentos centrais, sendo que estes estão circundados por nove fibras grosseiras nesta região e recobertos perifericamente por numerosas mitocôndrias (bainha mitocondrial); a peça principal constitui centralmente do axonema e o conjunto de fibras grosseiras; e finalmente a peça terminal contém apenas o axonema central recoberta pela membrana plasmática (plasmolema) (MIES FILHO, 1987).

\section{ALTERAÇÕES MORFOLÓGICAS DO ESPERMATOZÓIDE}

Blom (1972) citado por Mies Filho (1987), descreve que a classificação das patologias espermáticas descritas por Rao (1971) em primárias e secundárias julgou sendo mais conveniente uma classificação que tivesse por base à anatomia espermática, sendo assim denominadas em defeitos maiores e menores.

Colas (1980) citado por Medeiros (2004) as alterações na morfologia do espermatozóide podem comprometer seu poder fecundante, estas alterações podematingir quaisquer estruturas como o acrossomo, cabeça, peça intermediária, cauda, podendo atingir simultaneamente mais de uma estrutura. As respectivas alterações serãodescritas a seguir:

\section{a) Alterações acrossômicas}

Conforme Sá et al (2002), citado por Medeiros (2004) esta estrutura precisa encontrar-se normal, pois é parte essencial da fertilização.

Aisen (2008) relata que o status do acrossomo é um dado importante de ser analisado já que uma alteração parcial ou total leva a uma incapacidade para fertilizar.

Segundo Blom (1950) citado por Medeiros (2004), o acrossomo destacado, ocasionado por abstenção prolongada do macho reprodutor, existe uma relação entre esta alteração e taxa de fertilidade.

Blom (1950) citado por Mies Filho (1987) relata que a permanência de um grânulo no acrossomo é uma anormalidade de caráter hereditário, sendo visualizado em lâmina corada ou em microscópio de contraste de fase sob forma de um ponto na margem anterior da cabeça do espermatozóide, este defeito pode levar a esterilidade absoluta devido à incapacidade de realizar a reação do acrossomo. Mies Filho (1987) cita que outras alterações do acrossomo são casos de espermatozóides apresentarem-se rugosos ou com 
contorno defeituoso na região anterior do acrossomo.

\section{b) Alterações da cabeça}

Segundo Derivaux (1980) citado por Medeiros (2004) os espermatozóides podem apresentar diversos tipos de defeitos de cabeça, tais como cabeças pequenas, grandes, globuliformes, lanciformes, piriformes e estreitas na base, indicando provavelmente uma má distribuição do material genético durante a divisão celular, já contorno anormal e cabeças duplas são características de má qualidade do espermatozóide.

\section{c) Alterações de peça intermediária}

Segundo Blom (197I) citado por Medeiros (2004) estas alterações ocorremdevido à má distribuição das camadas de mitocôndrias levando a peça intermediária apresentar-se de forma espiralada. A presença de gota proximal deve-se também a esta distribuição anormal que impedem a liberação da gota durante os processos de maturação celular.

\section{d) Alterações de cauda}

Segundo Blom (1971) citado por Medeiros (2004) a cauda pode apresentardiversas alterações, tais como, dobrada, enrolada na extremidade, gota citoplasmática distal, sendo relacionadas com disfunções do epidídimo, podendo também aparecer formações teratológicas com duas ou mais caudas. O forte enrolamento presente nas caudas é devido ao rompimento das fibrilas.

\section{CICLO DO EPITÉLIO SEMINÍFERO}

González (2006) relata que os ciclos do epitélio seminífero são associações celulares que se repetem ao longo dos túbulos seminíferos durante a espermatogênese. Estas associações são caracterizadas pela morfologia semelhante do grupo.

Hafez (2004) define o ciclo do epitélio seminífero como uma série de modificações entre duas aparições de associação celular ou de estágios de desenvolvimento em determinada região do epitélio seminífero. Sendo utilizada a terminologia de espermiogênese para classificar os vários estágios do ciclo.

Suñe (2007) enfatiza que em qualquer corte transversal do epitélio seminífero os 
vários tipos celulares presentes formam associações celulares bem definidas, sofrendo modificações cíclicas. Estas combinações celulares ocorrem em determinados segmentos, desta forma, ao confeccionar um corte histológico transversal do testículo, visualiza-se determinados elementos celulares, e no corte perpendicular aos túbulos seminíferos é observado uma variedade celular maior.

Ainda o autor cita que existe dois tipos de classificação, o primeiro referente às trocas morfológicas das células e o segundo quanto ao desenvolvimento acrossômico das espermátides. Estes estágios representam modificações que ocorrem naturalmente e continuamente, com relação às modificações celulares, numa dada região do túbulo seminífero.

Mies Filho (1987) enfatiza a duração do ciclo no carneiro é de Io,4 dias; já o processo da espermatogênese pode ser estimada em aproximadamente 48 dias nesta espécie.

Este ciclo é importante, pois é a garantia de liberação constante de espermatozóide, reduzindo competição por hormônios e metabólitos usados em determinado estágio, facilitando a maturação do espermatozóide no epidídimo através do fluxo contínuo destes, ocorrendo assim a garantia de um constante fluxo de fluído no túbulo seminífero (SUÑE, 2007).

\section{PUBERDADE}

De acordo com González (2006) a puberdade compreende a época em que o macho torna-se capaz de fertilizar uma fêmea. Necessitando de um comportamento sexual que permita a cópula e possuir número suficiente de espermatozóides fecundante. Hafez (2004) relata que a puberdade tem início entre os seis e sete meses de idade do animal. A puberdade sofre influência do ambiente físico, raça dos progenitorese heterose. Porém, o peso corpóreo esta ligado mais intimamente a esta característica do que a própria idade deste indivíduo.

Galina e Valencia (2006) afirmam que o começo da puberdade ocorre com o crescimento testicular e a produção espermática. $O$ início da espermatogênese varia entre raças, tendo início aos dois ou três meses de idade, independente da época de nascimento. Os primeiros espermatozóides a constituírem o ejaculado aparecem seis meses de idade e com baixa qualidade, sendo que esta aumenta de forma progressiva com a idade. 


\section{MATURAÇÃO DO ESPERMATOZÓIDE}

Segundo González (2006) os espermatozóides produzidos pelos mamíferos não têm capacidade de fertilização quando recém produzidos pelos testículos, somente adquirem esta quando passam pelo processo de maturação espermática na cauda do epidídimo quando começam a se locomover com movimentos ativos e progressivos e permanecer por um tempo no trato reprodutivo da fêmea.

Para Galina e Valencia (2006) o processo de maturação termina com a capacitação do espermatozóide no trato reprodutivo da fêmea em cio.

De acordo com Hafez (2004) a capacitação impede a ativação prematura do acrossomo até que o espermatozóide chegue na região do istmo no útero.

O acrossomo não sofre modificações na sua estrutura durante a capacitação do espermatozóide sendo então a fase que antecede e prepara o espermatozóide para a reação do acrossomo (GONZÁLEZ, 2006).

Localizada na parte superior da cabeça do espermatozóide o acrossomo possui forma de capuz, apresentando pelo menos 20 enzimas, entre elas a hialuronidase, acrosina, proteinase, entre outras. Estas enzimas são importantes para a passagem do espermatozóide através das células que envolvem o ovócito (KOLB, 1980).

González (2006) cita que quando o espermatozóide não é viável, o acrossomo autodigere-se constituindo uma reação falsa do mesmo, devendo ser diferenciada da reação verdadeira nos espermatozóides vivos.

\section{SAZONALIDADE}

Segundo Aisen (2008) a melatonina é o hormônio responsável pela sincronização do ritmo anual de reprodução.

De acordo com Pugh (2005) os carneiros são reprodutores sazonais, pois durante a época do ano onde existe menos horas de luminosidade faz com que ocorra um aumento na qualidade do esperma, no volume e na atividade sexual, levando a um acréscimo de alguns centímetros no perímetro escrotal do mesmo.

Ainda o autor relata que a melatonina é secretada pela glândula pineal durante o período foto negativo, ou seja, períodos com mais escuridão. $O$ aumento da produção deste hormônio é determinado como o início da estação de monta. 
Segundo Galina e Valencia (2006), a melatonina é captada pela retina, onde o sinal luminoso se transforma em sinal nervoso e depois chega para a glândula pineal, onde o sinal nervoso é transformado em um sinal hormonal, possuindo níveis mais altos durante o período de escuridão e o mais baixo quando aumenta as horas de luz, a melatonina é então, o ponto final do itinerário hormonal que determina a modificação do pulsatilidade do GnRH (hormônio liberador de gonadotrofina).

Para Del Campo (1980), além do foto período negativo para o início da estação reprodutiva nos machos, está relacionada também uma série de fatores como genético, nutricional e clima.

\section{EXAME ANDROLÓGICO}

COLÉGIO BRASILEIRO DE REPRODUÇÃO ANIMAL - CBRA (1998) relata que este exame tem como princípio avaliar a aptidão reprodutiva de um macho indicado à seleção e comercialização, avaliar o potencial pré-estação de monta, diagnosticar infertilidade ou sub-infertilidade, diagnosticar o início da puberdade, selecionar reprodutores para criopreservação de sêmen, avaliando-se a saúde geral, hereditária e genital.

Ainda CBRA (1998) para realizar este exame é necessário seguir uma ordem mínima de etapas, para se obter uma boa veracidade com os resultados obtidos deste.

Segundo Pugh (2005) o exame adequado consiste em uma avaliação do escroto e testículos, seguidos da avaliação do sêmen, pois na rotina deste exame não está inclusaa avaliação da libido do carneiro ou a sua capacidade física para realizar a cópula.

Ainda este autor relata que é necessário combinar os achados da circunferência escrotal, motilidade, vigor e porcentagem de espermatozóides normais, para prever sua utilização como reprodutor. Carneiros classificados como não satisfatório após sessenta dias é necessário passar por um novo exame andrológico.

As etapas serão descritas nos tópicos a seguir.

\section{IDENTIFICAÇÃO}

De acordo com Aisen (2008), os animais destinados a realizar este exame precisam ser identificados com brincos de fácil visualização.

CBRA (1998) descreve que são necessárias informações do proprietário/propriedade, como nome, endereço, telefone para contato ou fax. 
Necessitam ser informado na ficha técnica do exame, nome do animal, tatuagem, número de registro, data de nascimento, raça, peso e filiação.

\section{EXAME DOS ÓRGÃOS EXTERNOS}

Pugh (2005) cita que se deve palpar o escroto para garantir a presença dos dois testículos e neste momento avaliar a consistência e tamanho de ambos, sendo fisiológico apresentar-se firmes e de tamanhos iguais. Qualquer tumefação localizadaou presença de áreas endurecidas deve ser observada e feitas os devidos apontamentos na ficha de campo deste exame.

Ainda o autor destaca a necessidade de quantificar a circunferência escrotal, tal procedimento deve ser feito com seguintes passos: tracionar ambos os testículos ventralmente e medir seu maior diâmetro com auxilio de uma fita métrica.

Segundo Pugh (2005) a cabeça e a cauda do epidídimo necessitam ser palpados, pesquisando possíveis alterações neste órgão, como tumefações, dor ou sinais de inflamações, assim como examinar o cordão espermático, investigando deformidades no plexo vascular e ductos deferentes.

Ainda de acordo com este autor, a circunferência mínima para carneiros jovens é de 30 centímetros $(\mathrm{cm})$, que pesem acima de 68 quilogramas $(\mathrm{kg}), 33 \mathrm{~cm}$ para carneiros com 12 a 18 meses, $36 \mathrm{~cm}$ para carneiros que pesem acima de IIokg, conforme especificado na tabela I. A circunferência escrotal pode ter variações conforme a época do ano, pois fora da estação reprodutiva é de se esperar medidas testiculares menores $(0,5$ a $1,5 \mathrm{~cm}$ menor).

Tabela I - Circunferência escrotal de carneiros antes da estação de monta

\begin{tabular}{cccc}
\hline 8 a 14 meses & & Acima de 14 meses de idade \\
\hline Tamanho & Classificação & Tamanho & Classificação \\
Menor que $28 \mathrm{~cm}$ & Questionável & Menor que $32 \mathrm{~cm}$ & Questionável \\
28 a $36 \mathrm{~cm}$ & Satisfatório & 32 a $40 \mathrm{~cm}$ & Satisfatório \\
Maior que $36 \mathrm{~cm}$ & Excepcional & Maior que $40 \mathrm{~cm}$ & Excepcional
\end{tabular}

Fonte: adaptado de Yarney T. A et al, citado por Pugh (2005). 


\section{MÉTODOS DE COLETA DE SÊMEN}

Existem dois métodos para coleta de sêmen em carneiros: eletroejaculação (EE)e vagina artificial (VA) (HAFEZ, 2004).

Para CBRA (1998) deve ser documentado o método de coleta utilizado no laudo do exame andrológico.

\section{VAGINA ARTIFICIAL}

Aisen (2008) descreve que para realizar este método de coleta é indispensável à presença de uma fêmea devidamente contida, podendo ser contenção manual ou com utilização de troncos adequados para este fim.

FUNDAÇÃO BRADESCO (2006), considera o método que mais se aproxima da monta natural, pois faz com que o carneiro realize a cópula em um aparelho adaptado de maneira que a ejaculação se proceda dentro deste.

Hafez (2004) cita que para coleta de sêmen utilizando este procedimento precisase de manequins, como uma fêmea estimuladora, outro macho ou macho castrado.

Ainda $\mathrm{Hafez}(2004)$ a vagina artificial é um tubo que pode medir de 20 a $25 \mathrm{~cm}$ de comprimento (modelo clássico), e cinco a sete centímetros de diâmetro e umamucosa de borracha que necessita de lubrificação no momento da coleta e uma temperatura entre 42 a 46 graus Celsius (o-C) (Figura 2).

Mies Filho (1987) descreve diversos modelos de vagina artificial, citando o modelo curto (Mies Filho, 1962) que possui vantagens sobre outros modelos por este depositar o sêmen diretamente ao tubo coletor, sendo de fácil manipulação, não necessita lubrificação, de pronta recuperação e acompanhamento de toda a mecânica do coito (Figura 2). Qualquer modelo de vagina artificial a ser utilizado requer carneiros que saltem sobre as ovelhas previamente contidas para este propósito (DEL CAMPO, 1980).

Para realizar a operação de coleta com o uso da VA é necessário seguir os seguintes passos: assegurar o instrumento com a mão direita e com a esquerda desviar ligeiramente o prepúcio para que ocorra a penetração do pênis no aparelho, ocorrendo assim a imediata ejaculação, em muitos casos a pressão exercida pela vagina constitui- se no único estímulo para tal, conforme visualizado na figura três (MIES FILHO, 1987).

De acordo com Mies Filho (1987), não é aconselhável deixar rugas na mucosado 
tubo coletor, assim como, evitar o excesso de lubrificante, pois poderá juntar-se ao sêmen e também não utilizar os que apresentarem formulação desinfetante, evitar que contenha água no trajeto do tubo onde o sêmen passará, controlar a temperatura da água dentro do tubo para que não ultrapasse os limites deste no momento da cópula, manipular o pênis em direção a VA somente através do prepúcio, evitando assimqualquer lesão, e realizar limpeza no prepúcio antes da coleta se faz necessário para evitar o deslocamento de sujidades neste momento.

FUNDAÇÃO BRADESCO (2006), salienta que é necessário proteger o tubo coletor para evitar o contato da luz solar com o sêmen ejaculado.

Figura 2-Modelos de vaginas artificiais

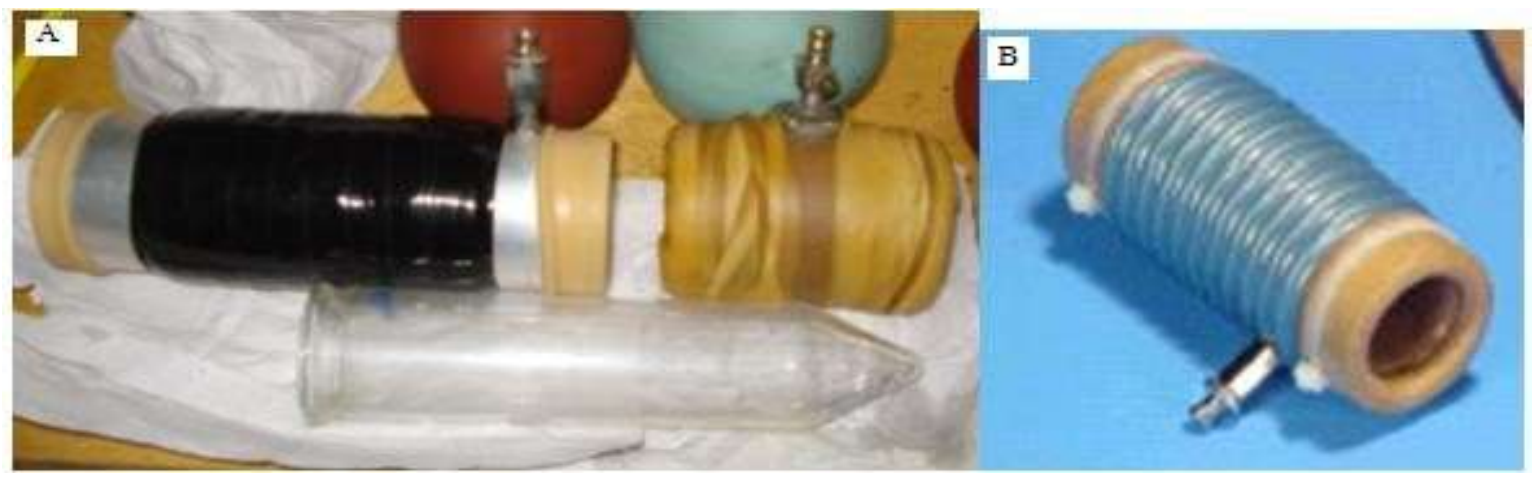

Fonte fig B: www.walmur.com.br

\section{ELETROEJACULADOR}

Del Campo (1980) cita que foi um veterinário australiano Gunn (1936) que aprimorou o método ao excitar o centro de ejaculação localizada na medula espinhal na altura da quarta vértebra lombar.

Mies Filho (1987), descreve que o animal pode ejacular com ou sem ereção, dependendo do alcance dos estímulos produzidos. A excitação mais posterior (região lombo sacra) resulta em uma resposta da ereção ocorrendo também à expulsão das secreções das glândulas acessórias, já excitações mais anteriores (região lombar) produzem um efeito mais acentuado da ejaculação. As variações do ejaculado com este método podem fornecer falsos resultados, uma vez que um animal fértil pode passar como infértil no exame com EE e o mesmo animal sendo coletado com VA, avaliado 
como apto à reprodução naquele momento.

Hafez (2004) a coleta por eletroejaculador é realizada através de uma sonda elétrica bipolar introduzida no reto do animal. Um estímulo elétrico de baixa voltagem é aplicado por dois a quatro segundos, seguidos de intervalos de ro a 20 segundos até a ejaculação. $\mathrm{O}$ volume e a concentração do ejaculado por este método é variável. Pode ser encontrada presença de urina no coletado, além de ser um método estressante para o carneiro. Segundo Aisen (2008), o estimulador elétrico, via retal, é alimentado mediante corrente de 220volts com transformador redutor e alguns modelos possuem também bateria 12 volts ou um dínamo.

Ainda Aisen (2008), relata a metodologia do EE, onde primeiramente é feita a contenção do carneiro, em estação ou decúbito lateral, introdução do eletrodo via retal, com devido cuidado, após realizar inicialmente três pulsos curtos de dois a três segundos de duração cada, com cinco segundos de intervalo, depois aplicar de um a três estímulos mais prolongados com duração de cinco a dez segundos, para estimular a ejaculação, recolhendo o sêmen no tubo coletor.

\section{EXAME DE SÊMEN}

Para adequada avaliação do sêmen é necessária a avaliação da motilidade e da morfologia (PUGH, 2005).

\section{EXAME IMEDIATO}

Segundo CBRA (1998), existem características físicas do ejaculado que devem ser observadas e anotadas na ficha, determinando assim o exame imediato. Características como volume, aspecto, turbilhão (movimento de massa), motilidade, vigor, devem ser examinados imediatamente após a coleta.

Aisen (2008) cita como pontos importantes, a cor e volume. A cor do ejaculado do carneiro é branco cremoso fisiologicamente, devendo ser descartadas amostras que possuírem coloração branco-rosado ou acinzentado, o que indica a existência de sangue ou algum tipo de infecção no aparelho reprodutor. $O$ volume médio é de um mililitro a cada ejaculado, com variações entre raças, idade, estado geral do macho e habilidade do operador.

Para a FUNDAÇÃO BRADESCO (2006) o sêmen de carneiros apresenta as 
seguintes características fisiológicas:

- Volume: com variação de o,5 a 2,oml (figura 4);

- Cor: apresenta-se fisiologicamente branco-pérola ou marfim (figura 4). Podendo apresentar-se esverdeado quando misturado com pús, avermelhado quando o sangue estiver presente ou amarelado em presença de urina;

- Aspecto: avaliação visual, determinação de sua aparência (cremoso, leitoso, opalescente e aquoso) tem relação à concentração de espermatozóides, e;

- Movimento dos flocos: macroscopicamente determina-se como ativo, médio, lento ou imóvel, conforme figura quatro.

CBRA (1998) é necessário possuir um microscópio de campo para visualizar a motilidade logo após a coleta, onde se coloca uma gota de sêmen sobre uma lâmina previamente aquecida a $37^{\circ} \mathrm{C}$ e sobrepor uma lamínula para verificar o mesmo em objetiva de ro a 2ox, utilizando uma escala de porcentagem, conforme a proporção de motilidade dos espermatozóides. Neste mesmo momento avalia-se o vigor, sendo subjetiva esta avaliação, utilizando uma escala de o a 5 , onde se observa a intensidade do deslocamento da massa.

Figura 4 - Avaliação do ejaculado logo após a coleta

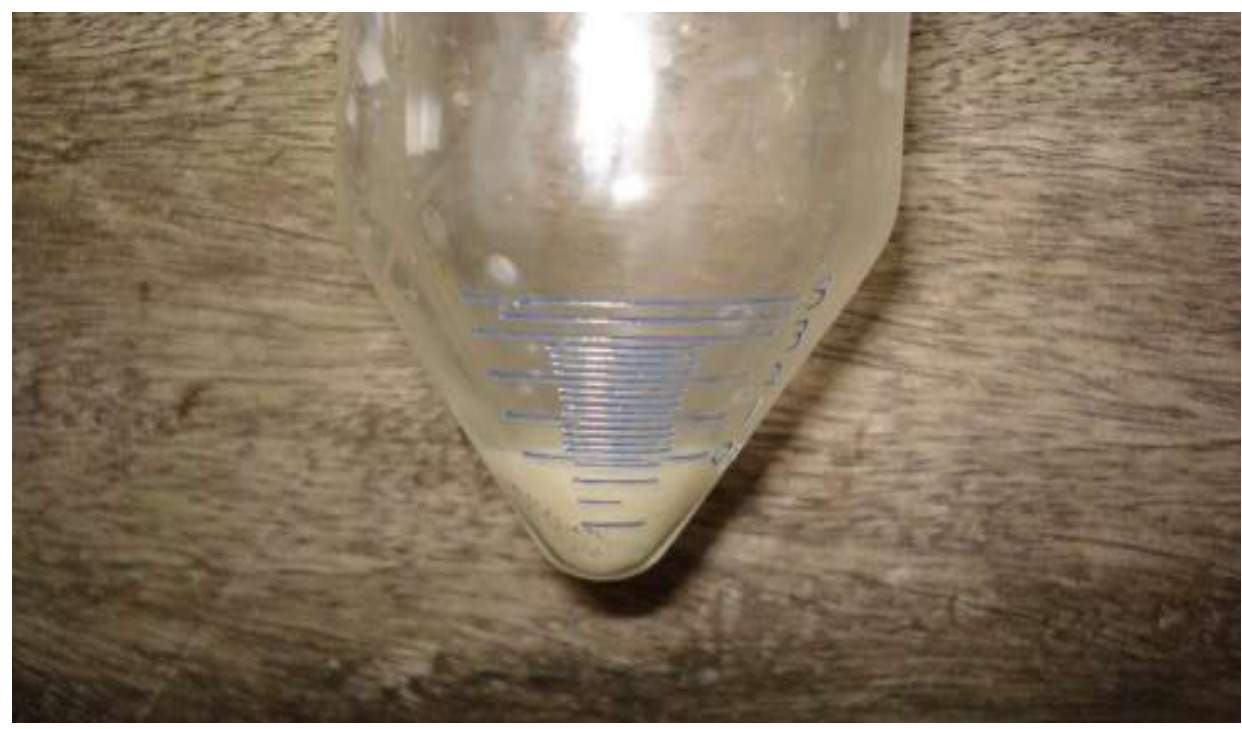

Exame Mediato 


\section{COMPÕEM O EXAME MEDIATO:}

\section{a) Concentração Espermática}

Aisen (2008) a concentração de espermatozóides por ejaculado pode ser determinada por meio de contagem em microscópio através do hemocitômetro (câmara de Neubauer) ou pode verificar-se junto ao exame imediato através do turbilhonamento estimando esta concentração.

Hafez (2004) comenta que para determinar a concentração existem outros métodos, tais como, calorímetro ou espectrofotômetro.

Ainda o autor cita que a contagem de células com a câmara de Neubauer é um método demorado, porém muito acurado.

Segundo Mies Filho (1987), para determinar a concentração de espermatozóides por ejaculado, deve-se colocar 20 milímetros cúbicos $\left(\mathrm{mm}^{3}\right)$ de sêmen diluídos em quatro mililitros ( $\mathrm{ml}$ ) de solução formol salina tamponado, ocasionando uma diluição de i:20o por amostra.

Conforme Egon e Moraes (2005) o uso do diluente formol salina tamponado seria para estudos posteriores de concentração e morfologia, podendo ser conservadopor até dois anos em temperatura ambiente, pois mata os espermatozóides sem alterar suas estruturas.

De acordo com CBRA (1998) para realizar a contagem em câmara de Neubaueré necessário seguir os seguintes procedimentos: o sêmen deve estar previamente diluído em formol salina tamponado ou citrato de sódio formolado, homogeneizar corretamente a amostra diluída antes de retirar parte para o preenchimento da câmara com auxílio de um tubo capilar, para esta etapa deve-se depositar o preparado sob a lamínula até completar toda superfície e logo preencher o outro lado. Após espera-se cinco minutos para as células ficarem em repouso no fundo da câmara.

Conforme Egon e Moraes (2005) a câmara de Neubauer possui um total de 25 quadrados de o,04 milímetro quadrado $\left(\mathrm{mm}^{2}\right)$ sendo considerados grandes, e 400 quadrados de $0,0025 \mathrm{~mm}^{2}$ sendo considerados pequenos, dentro de cada grande existem 16 pequenos e aqueles estão separados entre si por linhas triplas.

Segundo CBRA (1998), para realizar a contagem utiliza-se microscópio de campo claro, com objetiva de iox e $40 x$ contando pelo menos cinco quadrados grandes, ou seja, 
sobre um total de $10 / 25 \mathrm{~mm}^{2}$ de área, em cada lado da câmara. A porcentagem acima de io por cento (\%) de diferença entre os lados é indicativa de falha na homogeneização ou preenchimento inadequado.

Ainda o autor cita que a concentração espermática sofre variações devido a fatores extrínsecos como o método de coleta, freqüência de atividade do reprodutor, condicionamento físico do mesmo e fatores intrínsecos como idade, estado, higidez dos testículos e seu tamanho. A fórmula utilizada para determinar a concentração é feita a partir da divisão do número de espermatozóides contados com fator de diluição (I:20o), número de quadrados grandes contados, dividido por número total de quadrados grandes e altura da câmara (I/Io).

\section{b) Morfologia espermática}

CBRA (1998), cita que os métodos mais utilizados para a confecção das lâminas para avaliar a morfologia espermática é a lâmina corada e câmara úmida (com auxílio de microscopia em contraste de fase). Para confeccionar a lâmina corada é necessário fazer um esfregaço utilizando uma gota do sêmen sobre aquela previamente aquecida a

$37^{\circ} \mathrm{C}$ e após realizar uma coloração no laboratório, por exemplo, utilizando o corante eosina-nigrosina.

Ainda CBRA (1998) descreve que a confecção da câmara úmida ocorre após depósito de gotas do ejaculado, quantas necessárias para obter um aspecto leitoso nesta solução com formol salina tamponado. Previamente a confecção da lâmina, homogeneízase a solução para utilizar uma gota sobre a lâmina limpa e seca, após cobre-se com uma lamínula e delicadamente pressiona-se este conjunto com auxílio de um papel filtro, para retirar o excesso de líquido, podendo também fixar a lamínula com esmalte cosmético possibilitando assim uma maior durabilidade da mesma.

De acordo com Pugh (2005) o examinador deve contar no mínimo cem espermatozóides por lâmina, para assim determinar a porcentagem de espermatozóides normais. Os defeitos mais encontrados são denominados como primários, que se referem a patologias espermáticas na cabeça e porção média e secundários atribuídos a defeitos de cauda.

CBRA (1998) descreve os padrões desejáveis para carneiros de monta natural é de $70 \%$ para motilidade progressiva, três de vigor, 3\% de turbilhão e $20 \%$ total de 
espermatozóides anormais. Já para sêmen congelado ovino os valores fora do padrão são: o volume da dose inferior a $0,15 \mathrm{ml}$, motilidade progressiva menor que $30 \%$, vigor inferior a três, defeitos totais de espermatozóide maior que 20\%, defeitos maiores acima de 10\% e concentração espermática menor que quarenta milhões por dose.

Segundo Aisen (2008), relata que as anormalidades espermáticas podem ser classificadas em primárias, onde as alterações originam-se durante o processo de espermatogênese, secundárias, cuja alteração ocorrem no decorrer da passagem do espermatozóide pelo epidídimo e terciárias, nesta classe estão incluídas as alterações que o espermatozóide sofre após o ejaculado ou durante a manipulação do mesmo.

\section{ANÁLISE DE SÊMEN CONGELADO DE CARNEIROS}

Colas et al (1982) apud Mies Filho (1987), o sêmen congelado dos carneiros possuem índices de conservação da fertilidade 58,8\% para períodos até 18 meses e 59,4\% entre sete a oito anos.

Para Moraes (2002) o procedimento da coleta, embalagem e o processo de congelamento precisam ser realizados seguindo minuciosamente as técnicas destes processos, pois podem comprometer a integridade do espermatozóide o que resulta numa taxa de fertilidade variável entre o a $40 \%$ quando utilizado as técnicas de inseminação cervicais.

Fiser et al (1991) citado por Bag (2002) relata que a manutenção da motilidade mais alta do sêmen, durante o processo de congelamento, reflete uma maior probabilidade da sobrevivência deles dentro da área genital feminina após o descongelamento. Ainda os autores enfatizam que análises realizadas após o descongelamento são iguais ao de sêmen fresco já citado anteriormente, o que muda são os resultados esperados após o descongelamento.

Aisen (2008) comenta que o processo de congelamento de sêmen afeta a motilidade e rompe as membranas dos espermatozóides.

Salamon e Maxwell (1995) citado por Bag (2002) cita que os espermatozóides dos carneiros são sensíveis às mudanças de temperatura extrema durante processos frios alterando a integridade de suas membranas.

Matiner et al (1969) apud Mies Filho (1987) comentam que o sêmen congelado, no trato reprodutivo da ovelha, sofre uma redução em torno de quatro vezes sobre o número 
total de espermatozóides.

\section{DUPLA COLORAÇÃO COM AZUL DE TRIPAN E GIEMSA}

Segundo Didion (1989) o procedimento de coloração simultânea tem comoobjetivo detectar espermatozóides viáveis e o status do acrossomo utilizando o Azul de Tripan para sinalizar os espermatozóides vivos e mortos e o corante Giemsa detecta a presença ou ausência do acrossomo, esta dupla coloração permite a diferenciação das reações verdadeira e falsa do acrossomo.

De acordo com Hafez (2004) a técnica de dupla coloração tem como finalidade detectar a viabilidade e a integridade do acrossomo.

Conforme Didion (1989), os espermatozóides que não apresentam alteração permanecem incolores e aqueles com alteração na região postacrossoma apresentam-se corados de azul. A dupla coloração é uma técnica útil tanto para a viabilidade do esperma como para o status acrossomal aplicado rotineiramente em laboratório.

A técnica de dupla coloração descrita por Didion (1989) é feita adicionando o,ıml de sêmen em um mililitro de meio de fertilização, após remover duzentos microlítros $(\mu 1)$ da suspensão lavada, logo adicionar junto ao pellet o,2ml de Azul de Tripan a dois por cento. Neste momento os tubos devem ser incubados por io minutos em banho-maria. Depois da incubação os espermatozóides são diluídos em dois a três mililitros do meio de fertilização e centrifugado (7oo giros por 6min), então o sobrenadante é dispensado e adicionado ao pellets dois a três mililitros de albumina livre de fecundação e centrifugado como anteriormente. Esta etapa é repetida até que a suspensão estiver azul claro, duas lavagens poderão ser suficientes, de acordo com Didion (1989).

Ainda este autor relata que nesta técnica precisa-se retirar io a $20 \mu 1$ da suspensão para fazer o esfregaço para a coloração, necessitando ser secadas a $40^{\circ} \mathrm{C}$ ao ar livre (córrego de ar). Só então, ser coradas durante 35-40 minutos em solução de Giemsa 10\% com água destilada. Após estas lâminas são enxaguadas em água corrente destilada e postas para secar.

Os resultados encontrados neste trabalho foram os seguintes: que o Giemsa tem habilidade de detectar espermatozóide com ou sem a presença de acrossomo e o Azul de Tripan tem habilidade de detectar vivos e mortos. A porcentagem de espermatozóides 
vivos sem acrossomo nos carneiros aumentou significativamente após quinze minutos, se mantendo até os sessenta minutos (DIDION, 1989).

\section{DISCUSSÃO}

O exame andrológico envolve uma série de técnicas desde a avaliação dosórgãos externos, coleta de sêmen até as avaliações laboratoriais do mesmo. O exame se divide em duas etapas: o exame imediato, concordando com FUNDAÇÃO BRADESCO (2006), deve ser avaliado as características fisiológicas da espécie ovina e o mediato que é composto por análises microscópicas do sêmen coletado.

Avaliava-se os testículos e epidídimos, observando simetria, consistência e circunferência escrotal. Concordando com o Pugh (2005) quando afirma que a simetria escrotal deve existir, assim como mobilidade testicular e consistência firme do mesmo. Ainda concordando com o autor sobre a importância de palpar a cabeça e cauda do epidídimo para descartar possíveis alterações.

Concordando com o Pugh (2005) quando este relata a importância de examinar o carneiro sentado para verificar o apêndice vermiforme e sua integridade; neste momento podem-se também examinar os testículos. Aisen (2008) relata que no exame imediato é importante avaliar a coloração do ejaculado e o volume. Já CBRA (1998) concorda com Aisen (2008) e acrescenta o aspecto, movimentação de massa, motilidade e vigor.

Para Del Campo (1980) o volume do ejaculado de um carneiro varia de o,8 a r,oml discordando da FUNDAÇÃO BRADESCO (2006) e Hafez (2004) que relatam a variação é de 0,5 a 2,oml por ejaculado. Porém estas variações podem ocorrer conforme época do ano, raças, idade e estado nutricional de cada indivíduo.

O movimento em massa é um dado subjetivo da concentração espermática e tem um valor importante no exame imediato concordando com Del Campo (1980), que salienta esta avaliação e acrescenta a intensidade da mobilidade, da concentração e porcentagem de espermatozóides vivos. Após a coleta as amostras são levadas para análises laboratoriais concordando com CBRA (1998) quando cita concentração espermática e morfologia dos espermatozóides como principais exames mediatos.

O exame de concentração espermática nem sempre se faz necessário, concordando com Del Campo (1980) que relata que ejaculados provindos de meios como o eletroejaculador não retrata com precisão esta característica, pois aumenta o volume do 
ejaculado porém com uma queda na concentração espermática.

Para Pugh (2005) existe uma relação entre concentração em um mililitro e a coloração do ejaculado, subjetivamente nebulosa, leitosa, cremosa suave, cremosa e cremosa espessa, caracterizam-se respectivamente $700 \times 10^{6}, 2.000 \times 10^{6}, 3.000 \times 10^{6}, 4.000 \times 10^{6}$, $5.000 \times 10^{6}$ em um mililitro quando realizado a contagem objetiva na câmara de Neubauer, concordando com Mies Filho (1987) onde afirma que os valores variam dois a cinco bilhões em um mililitro do sêmen ejaculado.

Para verificação da morfologia espermática foi realizado durante o estágio curricular à confecção de lâminas coradas ou por contraste de fase. CBRA (1998) concorda com Mies Filho (1987) quando este cita que o espermiograma pode ser obtido com a utilização de colorações apropriadas e microscopia de contraste de fase.

CBRA (1998) discorda de Pugh (2005) quando este relata que se deve contar pelo menos roo células, e considera-se um reprodutor satisfatório com porcentagem de células normais no mínimo 50\%. Pois para CBRA (1998) as características seminais são três bilhões de espermatozóide por ejaculado, 75\% de motilidade progressiva, 90\% de espermatozóides normais e não ultrapassando $20 \%$ de anormalidades morfológicas.

Pugh (2005) afirma que carneiros classificados como não satisfatórios apóssessenta dias é necessário passar por um novo exame andrológico, concordando com CBRA (1998) que enfatiza a importância de realizar um novo exame andrológico após sessenta dias na maioria das espécies.

Para FUNDAÇÃO BRADESCO (2006) existem dois métodos para coletar sêmen nos carneiros, são eles: vagina artificial e eletroejaculador, concordando com Del Campo (1980).

Mies Filho (1987), enfatiza a coleta utilizando vagina artificial, que é feita de maneira que o animal realize a cópula no aparelho específico ao ser desviado da vagina de um manequim ou de uma ovelha devidamente contida, concordando com Del Campo (1980).

Concorda-se com Aisen (2008) quando este relata a importância de realizar um treinamento com vagina artificial, pois os animais necessitam reconhecer a fêmea e os operadores como elementos idênticos chegando duas a quatro sessões semanais, duranteo aprendizado.

Mies Filho (1987) descreve que em alguns casos a pressão exercida pela vagina 
artificial é suficiente para o carneiro ejacular dispensando o calor, discordando em parte com Del Campo (1980) pelo fato de não existir calor, porém o mesmo autor concorda com Aisen (2008) sobre a temperatura no interior da vagina, $40^{\circ} \mathrm{C}$ a $44^{\circ} \mathrm{C}$.

FUNDAÇÃO BRADESCO (2006) concorda com Mies Filho (1987) quando aquele relata a importância do eletroejaculador, pois pode ser utilizada em animais incapacitados para monta ou em coletas de sêmen em reprodutores que não sejam condicionados a vagina artificial no exame andrológico.

As análises realizadas para verificar a qualidade do sêmen congelado, no decorrer do estágio curricular, foram semelhantes para o sêmen fresco, motilidade, vigor, concentração e morfologia espermática. Sendo considerado para Moraes et al (2007) concordando com CBRA (1998) como padrão seminal desejável, amostras que contenham no mínimo 40 milhões de espermatozóides com motilidade progressiva, ou seja, motilidade acima de 30\%, com vigor acima de três (com escala de zero a cinco), e aceitável até $20 \%$ de anormalidades espermáticas.

Aisen (2008) cita que um fator importante para recuperação espermática é o processo de mudança do estado sólido para o líquido, fazendo que a célula fique exposta a lesões, concordando com Galina e Valencia (2006), onde citam que os acrossomos, nos espermatozóides dos carneiros, são sensíveis ao processo de descongelamento.

Moraes et al (2007), utilizaram a técnica de dupla coloração descrita por Didion et al (1989) em uma de suas pesquisas. O procedimento é reliazado para analisar sêmen congelado de carneiros, concordando com a técnica descrita por Didion (1989) e citada por Hafez (2004) que relata os achados após as lâminas preparadas; são eles: morto com acrossomo intacto, morto sem a presença do acrossomo, vivo com acrossomo intacto e vivo após a reação acrossomal.

O meio utilizado para a realização da incubação foi o Dulbecco Mem discordando de Didion (1989) que descreve que para esta etapa é utilizado meio com albumina livre fecundação. A diferença no tempo de centrifugação entre a técnica descrita por Didion (1989)que aplicou 700 giros em seis minutos e a realizada no decorrer do estágio, 734 giros por cinco minutos, foi devido à diferença existente na força da rotação para se aproximar mais à técnica descrita por este autor.

Mies Filho (1987) cita a importância do acrossomo intacto, concordando com Aisen (2008) quando descreve que o status do acrossomo é um dos dados importantes para 
determinação na morfologia espermática, pois um dano parcial ou total leva a incapacidade de fertilizar.

González (2006) concorda com Didion (1989) quando cita que a falsa reação do acrossomo ocorre em espermatozóides mortos e a verdadeira em espermatozóides vivos pelo processo natural de capacitação e reação espermática.

\section{CONCLUSÃO}

Revisar as metodologias de avaliações reprodutivas nos ovinos, bem como conhecer as biotecnologias para acrescentar a produção se faz necessáro, já que a reprodução é um dos pilares para obter êxito dentro de uma propriedade rural.

Os avanços nos sistemas de criação dos ovinos estão cada vez mais constates fazendo com que o agronegócio busque com freqüência os meios descritos neste trabalho para tornar-se um meio rentável na ovinocultura.

\section{REFERÊNCIAS BIBLIOGRÁFICAS}

AISEN, E.G. Reprodução ovina e caprina. Io Ed. São Paulo: Medvet Livros, 2008. I- 3; 8; I2-I8; 57-66; 77-78; 81; 105-108; 122-I27pg.

BAG, S.; JOSHI, A.; NAQVI, S.M.K.; P.S. RAWAT; MITTAL, J.P. Effect of freezing temperature, at which straws were plunged into liquid nitrogen, on the post-thaw motility and acrosomal status of ram spermatozoa. Animal Reproduction Science. 72: p. $175-183,2002$.

BICUDO, S. D. Bases para a elevação da eficiência reprodutiva dos rebanhosovinos. In: SIMPÓSIO PAULISTA DE OVINOCULTURA, 7, Botucatu: 2006. FMVZ-UNESP.

COLÉGIO BRASILEIRO DE REPRODUÇÃO ANIMAL, Manual para exame andrológico e avaliação de sêmen animal. 2- Ed. Belo Horizonte, 1998, p. 12-13; 15-18; 22; 3538.

DEL CAMPO, A.D. Anatomia, fisiologia de la reproduccion e inseminacionartificial en ovinos. Uruguai, Editorial Hemisferio Sur, 198o, p. 6; 27-28; 31-33; 57-59; 
I24-I25; I29-I33; I43-I44; I48-I49; I90-I95.

EGON, J.F. e MORAES, G.V. Reprodução dos animais domésticos. Maringá, e-book, 2005 .

FUNDAÇÃO BRADESCO, Curso de Inseminação Artificial em Ovinos. 2006, p. 14-15; $17-18 ; 23$.

GALINA, C. e VALENCIA, J. Reproducción de los animales domésticos. $2^{\circ}$ Ed. México: Limusa, 2006. p. 38; 85-86; I0I-102; 105-109; I21-123; 136-137.

GONZÁLEZ, F.H.D. Introdução à endocrinologia reprodutiva veterinária. Porto Alegre: Gráfica UFRGS, 2006, p. 50-56 e 80-84.

GRANADOS, L.B.C. Aspectos gerais da reprodução de caprinos e ovinos. $I^{\circ}$ Ed. Campos dos Goytacazes: Universidade Estadual do Norte Fluminense Darcy Ribeiro, 2006, p. I2.

HAFEZ, E.S.E e HAFEZ B. Reprodução animal. $7^{\circ}$ Ed. São Paulo: Manole, 2004. p.5-9; I3-21; 57; 69-73; 97-98; 101; 103-104; III-II2; 370; 377-378; 390; 399-403; 401402.

IBGE. Dados sobre população ovina 2006. Disponível na internet em: www.ibge.com.br. Acesso: Io de setembro de 2008.

KOLB, E. Fisiologia veterinária. 4. Ed. Rio de Janeiro: Guanabara Koogan S.A., 198o,p. $382-384 ; 385-386 ; 388-391$.

LEÃO, K.M. Técnicas de inseminação artificial. Botucatu, 2003, p. 14-17.

MEDEIROS, A.A. Utilização do azul de bromofenol como método de coloração vital para a avaliação da morfologia do espermatozóide ovino. Fortaleza, dezembro, 2004, p. 3$5 ; 7-8$. 
MIES FILHO, A. Reprodução dos animais e inseminação artificial. Volume r e 2. $6^{\circ} \mathrm{Ed}$. Porto Alegre: Sulina, 1987. p. 45; 52-53; 62-70; 98-I04; IIo-II5; 368-380; 413; 418-419; 424-425; 439-440; 491; 513; 618.

MORAES, E.P.B.X.; SANTOS, M.H.B.; FILHO, C.R.A.; NEVES, J.P.; OLIVEIRA, M.A.L.; LIMA, P.F. Avaliação ultra-sonográfica do desenvolvimento embrionário- fetal de ovinos da raça Santa Inês. Ciência Animal Brasileira. Goiânia; v. 9: $n^{\circ}$ I: I48-I55, janeiro/março. 2008.

MORAES, J.C.F.; SOUZA, C.J.H.; JAUME, C.M.; OSÓRIO, J.A.; RIBEIRO, M. Desenvolvimento de Processos para uso de sêmen ovino conservado no estado líquido e congelado. EMBRAPA Pecuária Sul, Documentos. Bagé: 64: p. 15; 21; 27, outubro. 2007.

NETO, A.F. Ovino-caprinocultura, acreditando nas oportunidades, superandodesafios. Informativo AGROSUL. Porto Alegre, p.39-40, julho. 2008.

NETO, O.A.P. Manejo reprodutivo de ovinos. Porto Alegre: SENAR - ServiçoNacional de Aprendizagem Rural. p. 13-16; 33. 2000.

PUGH, D.G. Clínica de ovinos e caprinos. I. Ed. São Paulo: Roca Ltda, 2005, p. 145-153; І64-І66; I74-176; I79-г81.

SIMÕES, J.; FONTES, P., ALMEIDA, J.C. Diagnóstico de gestação e de patologias uterinas por ecografia em ruminantes, eqüinos e suínos. Versão online, 2008, p. 33- 40. 